\title{
Measurements of micro bubble nucleation temperatures in DNA solutions
}

\author{
Peigang Deng ${ }^{1}$, Yi-Kuen Lee ${ }^{1}$ and Ping Cheng ${ }^{2}$ \\ ${ }^{1}$ Mechanical Engineering Department, Hong Kong University of Science and Technology, \\ Clear Water Bay, Kowloon, Hong Kong \\ ${ }^{2}$ School of Mechanical and Power Engineering, Shanghai Jiaotong University, \\ Shanghai 200030, People's Republic of China \\ E-mail: meyklee@ust.hk
}

Received 8 March 2004, in final form 11 November 2004

Published 13 January 2005

Online at stacks.iop.org/JMM/15/564

\begin{abstract}
Measurements of micro bubble nucleation temperature in single-stranded DNA (ssDNA) solution with four different concentrations $(0.4,1,6.4$ and $10 \mu \mathrm{g}^{-1}$ ) and under different heat fluxes are presented in this paper. A micro thermal bubble was generated periodically by a micro bubble actuator under pulse-heating conditions. The bubble nucleation temperature was measured by employing a micro Pt heater as a self-sensing resistive temperature sensor, and the voltage signal was recorded by a $100 \mathrm{MHz}$ high-speed digitizer. By examining the temporal temperature variation of the micro heater during the pulse-heating period, one can observe a ' $\mathrm{V}$ ' shape temperature change for the cases when bubble nucleation occurred, which was speculated to be the beginning of bubble nucleation. It is found that (1) the onset bubble nucleation temperature increases with the DNA concentration and (2) at a fixed concentration, the bubble nucleation temperature increases with the heat flux from the micro heater. Based on a transient 3D heat conduction model, it is found that the size of the superheated region in the fluid just before bubble nucleation is comparable to the feature size of the micro heater, and relatively independent of the ssDNA concentration and heat flux.
\end{abstract}

\section{Introduction}

With the rapid development of micro lab-on-chip systems, also called the 'micro total analysis system', applications of micro ink-jet printing technology are emerging in many areas of biological and life science. Utilizing the actuation of either thermal bubble or piezoelectric material, ink-jet printing technology can realize micro level dispensing of bioactive fluids such as delivery of drugs and biological materials.

The operation of ink-jet printing is non-contacting, and it can deposit a small volume of liquid accurate to several picoliters. With the array design of the actuation cells in a printhead, the printing process can be high-throughput and fast in implementation. In recent years, ink-jet printing technology has been successfully used for protein deposition, DNA in situ synthesis and DNA deposition in a microarray format [1-6]. In addition, three-dimensional tubes of living tissue have been printed using modified desktop printers filled with suspensions of cells instead of ink, which is a first step towards printing complex tissues or even entire organs [7].

Compared to other actuation methods, thermal bubble based ink-jet printing has many distinct advantages such as: simple in structure, having no moving parts, low cost and easy to be integrated with IC control circuits, which make it prevalent in the current ink-jet printing markers. However, caution must be applied to use thermal bubble printing for dispensing bioactive fluids, say DNA deposition. The reason is that DNA strands might be broken or degraded either by the shearing stress acting on them due to the hydrodynamic movement of the fluids when the bubble grows and collapses, or by the local high temperature induced by the transient generation of the thermal bubble. It has been found that some pretreatment of the bioactive samples could lower this kind of damage and facilitate the ejection process. For example, in a study of using a bubble-jet printing device to eject DNA segments (presynthesized oligonucleotides) 
onto a glass surface to produce a DNA microarray, some physical properties of the DNA solution, such as the volatility, solubility, wettability, viscosity and surface tension, could be optimized by chemical additives in order to reduce possible high-temperature and hydrodynamic damage to the DNA [5]. In another example, where ink-jet printing was used for tissue engineering, the viscosity, electrical resistance and temperature of the printing fluid must be adjusted and optimized [7].

In our previous studies $[8,9]$, we have investigated the possibility of using a micro vapor bubble as an actuator for applications in micro bio-analytical systems, where a single bubble was generated exactly on the slim part of a specially designed non-uniform-width micro heater. It was shown that an asymmetric bubble growth-collapse cycle could introduce effective flow perturbations in the bulk fluid. More recently, we have investigated transient micro thermal bubble generation and its subsequent dynamic behavior in single-stranded DNA (ssDNA) solutions with particular emphasis on the effect of DNA concentration on bubble dynamics [10]. The reason for choosing ssDNA solution as the test fluid is because DNA hybridization between ssDNA (with one acting as a DNA probe, the other as target DNA) is the operational principle for many DNA-based biosensors. A distinct damping effect on the motion of the micro bubble was observed at high ssDNA concentrations, which was due to the dissipation effect of the ssDNA macromolecules on the bubble kinetics. In addition, to investigate the viscosity effect on the micro bubble dynamics in ssDNA solutions, the viscosity of the DNA solution was increased by adding different amounts of sucrose [11]. A distinct retardation effect on the motion of the micro bubble was observed at high viscosities, which was due to the dissipation effect of the viscosity on the bubble kinetics.

Recently, some research work on measurements of the bubble nucleation temperature by recording the resistance change of the heater has been carried out [12-15]. Avedisian et al [12] measured the bubble nucleation temperature of water on a micro Ta-Al heater $\left(65 \times 65 \mu \mathrm{m}^{2}\right)$ with a $5 \mu$ s voltage pulse, where the initiation point of bubble nucleation was determined by a well-defined 'inflection point' in a temperature-time curve. They found that the bubble nucleation temperature increased with the heating rate and the largest heating rate and highest nucleation temperature measured were $0.25 \times 10^{9} \mathrm{~K} \mathrm{~s}^{-1}$ and $556 \mathrm{~K}$, respectively. Gold et al [13] also adopted the definition of 'inflection point' to identify the nucleation temperature in their investigation of microscale explosive vaporization of water on a $\mathrm{Pt}$ wire. On the other hand, the bubble nucleation temperature can also be determined by simultaneously recording the temporal temperature variation of the heater and the bubble nucleation process using the ultra high-speed strobe microscope technique. For example, Yin et al [14] determined the instant of bubble nucleation by examining images taken by a CCD camera of the bubble generation process $(3.9 \mathrm{~ms}$ for low heat flux and about $25 \mu \mathrm{s}$ for high heat flux), where the delay time between the start of the heating and the light flash was controlled.

In the present study, we investigate micro thermal bubble nucleation in ssDNA solutions by a micro bubble actuator with particular emphasis on measurements of the bubble nucleation temperature at different DNA concentrations and heat fluxes, and the determination of the superheated region in the fluid just before bubble nucleation. During the pulse-heating period, the temporal temperature curve of the micro heater was measured by using a micro Pt heater as a self-sensing resistive temperature sensor, and the voltage signal induced by the resistance change of the micro heater was recorded by a $100 \mathrm{MHz}$ high-speed digitizer.

The bubble nucleation temperature was evaluated by examining the temporal temperature curve of the micro heater. A ' $V$ ' shape temperature change was observed for the cases when bubble nucleation occurred, which was speculated to be the beginning of bubble nucleation. To reveal DNA concentration effects on the onset bubble nucleation temperature, measurements were carried out at four concentrations: $0.4,1,6.4$ and $10 \mu \mathrm{g} \mu \mathrm{l}^{-1}$. Using $1 \mu \mathrm{g} \mu \mathrm{l}^{-1}$ ssDNA solution, bubble nucleation temperatures were measured under two pulse-heating power inputs: one for the case of onset bubble nucleation and the other at a larger heat flux. The heat flux from the heater, heating rate, bubble nucleation temperature and time in the present experiment are summarized, and a brief comparison of our results with results from similar research on micro boiling is given.

A transient 3D heat conduction numerical simulation was used to obtain the temperature distribution in the fluid adjacent to the heater before nucleation occurred in order to estimate the superheated region (over $373 \mathrm{~K}$ ). Note that $373 \mathrm{~K}$ $\left(100{ }^{\circ} \mathrm{C}\right)$ is considered to be a critical temperature for the 'safety' of DNA, because in many polymerase chain reactions (PCR) the denature temperature can be as high as $368 \mathrm{~K}$ $\left(95^{\circ} \mathrm{C}\right)$. Therefore, determining the superheated region in the DNA solution can give an estimate of the possible damage region to the DNA when a thermal bubble is formed.

\section{Experiment}

\subsection{Micro bubble actuator}

2.1.1. Design and fabrication of the micro bubble actuator chip. The design and fabrication of the micro bubble actuator chip were described in the previous experiments by Deng et al [10] for studying the micro bubble dynamics in ssDNA solutions. Figure 1(a) is an overall picture of the packaged micro bubble actuator chip, consisting of a specially designed micro heater $\left(10 \times 2 \mu \mathrm{m}^{2}\right)$ and the electric pad. Figure $1(b)$ is a close-up view of the micro heater under a microscope. To avoid direct contact of the DNA solution with the metal part of the heater, a gas-phase vacuum deposited Parylene N (diX-N ${ }^{@}$, Daisankasei Co., Japan) conformal coating was adopted after the packaging of the micro bubble actuator chip.

2.1.2. Control circuit of the micro bubble actuator. In this experiment, the micro heater was operated under pulse-heating conditions. The heating pulse was controlled by a switching circuit, which could provide a pulse width as short as a few microseconds. A schematic diagram of the experimental setup is shown in figure 2(a), and the control circuit for the heating pulse generator is shown in figure $2(b)$ (outside the dotted-line frame).

A programmable $8255 \mathrm{I} / \mathrm{O}$ card was used to generate a pulse train, which was sent to the base terminal of a high 


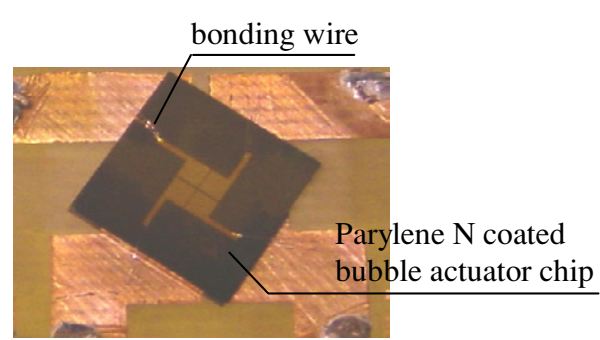

(a)

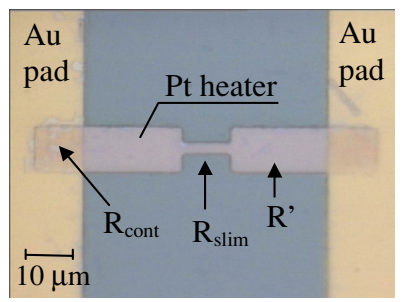

(b)

Figure 1. The micro bubble actuator: $(a)$ packaged micro bubble actuator chip and $(b)$ non-uniform-width micro heater.

gain transistor (ZTX689B, Zetex) to control the on/off heating process. Note that the transistor worked alternately at the cutoff and saturation regions to provide a pulse heating to the micro heater. The pulse generated from the $8255 \mathrm{I} / \mathrm{O}$ card was also sent to a CCD camera to trigger the video recording process during bubble generation. As will be mentioned later, this pulse signal was also sent to the trigger port of the data acquisition board to start the voltage signal recording process. The switching time of the transistor was at the nanosecond level. A dc power supply (model DF1731SB by Goldsource), which controlled the magnitude of the heating pulse in the micro heater, was connected to the collector terminal of the transistor and the emitter terminal was grounded. The pulse width, $\tau_{1}$ in figure $2(b)$, varied from several microseconds to milliseconds, and a typical heating pulse width of $1.66 \mathrm{~ms}$ was used in the present experiment. To avoid the overlapping of bubbles, a waiting pause $\tau_{2}$ of $1 \mathrm{~s}$ was inserted between two consecutive heating pulses. Note that the CCD camera recording process was synchronized with the heating process.

\subsection{Temperature measurement element}

2.2.1. Experiment arrangement and the control circuit. As an industry standard, a Pt resistance temperature detector (RTD) has the best stability and repeatability, and it offers virtually linear temperature-resistance response over the temperature range from 223 to $823 \mathrm{~K}$. In this experiment, we used a micro Pt heater as a self-sensing resistive temperature sensor to measure its average temperature variation during the vapor bubble nucleation period. The control circuit of the temperature measurement element is shown in figure $2(b)$ (inside the dotted-line frame).

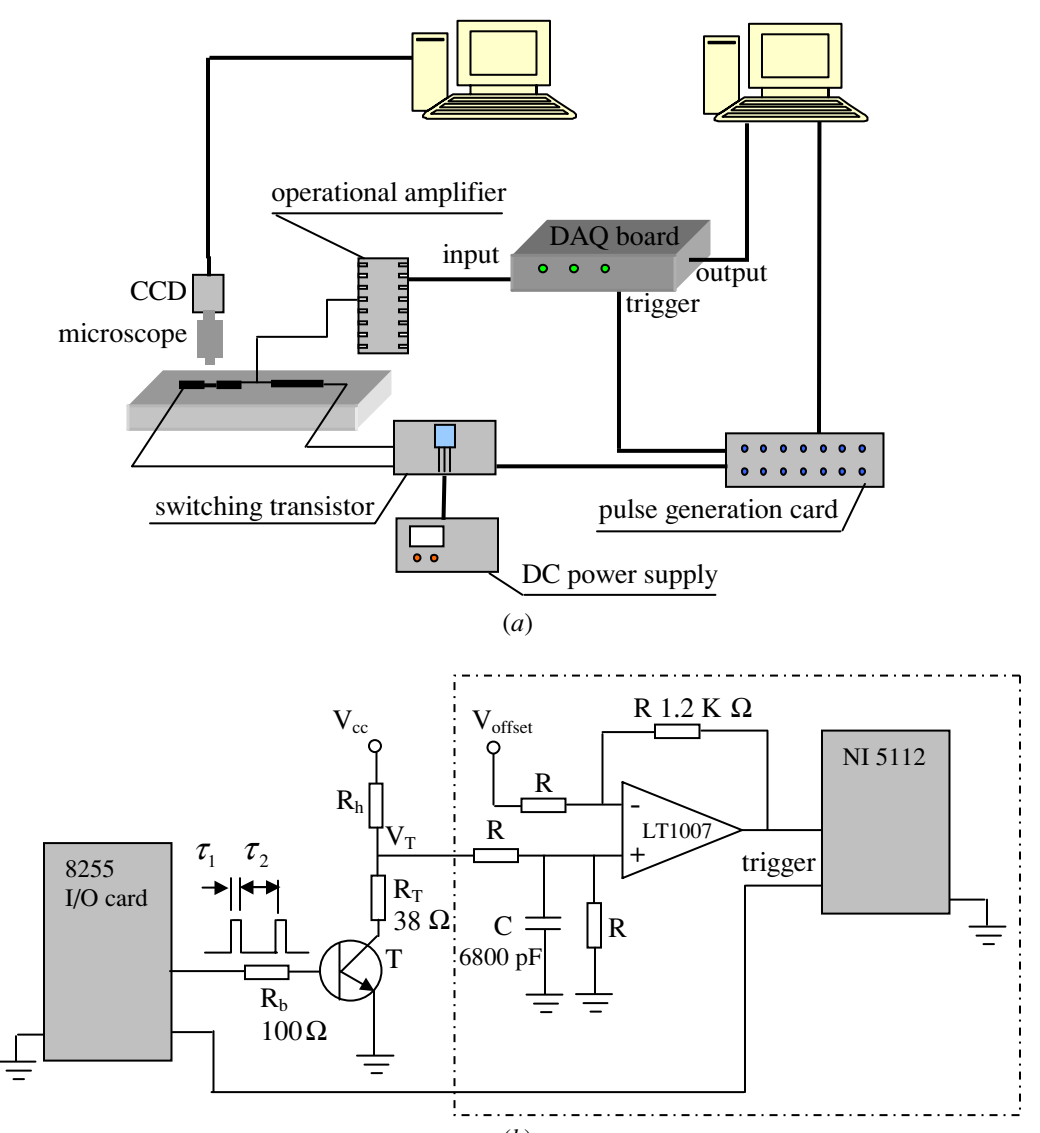

(b)

Figure 2. (a) Schematic diagram of the experimental setup and (b) control circuit of the micro heater and the temperature measurement system. 
A precise constant resistance resistor $\left(R_{\mathrm{T}}\right.$ in figure $\left.2(b)\right)$ was connected to the micro Pt heater $\left(R_{\mathrm{h}}\right.$ in figure $\left.2(b)\right)$ in series. When the heating process began, a constant voltage was imposed on these two serial resistors, and the resistance change of $R_{\mathrm{h}}$ led to a corresponding change in the voltage drop of $R_{\mathrm{T}}$. Thus, the average temperature variation of the micro $\mathrm{Pt}$ heater during the pulse-heating process could be examined by recording the voltage variation at the joint point of $R_{\mathrm{h}}$ and $R_{\mathrm{T}}$, indicated as $V_{\mathrm{T}}$ in figure $2(b)$. $V_{\mathrm{T}}$ can be expressed as

$$
V_{\mathrm{T}}=\frac{V_{\mathrm{cc}}-V_{\mathrm{ce}}}{R_{\mathrm{h}}+R_{\mathrm{T}}} R_{\mathrm{T}}+V_{\mathrm{ce}}
$$

where $V_{\mathrm{cc}}$ is the voltage input and $V_{\mathrm{ce}}$ is the saturation voltage drop between the collector and emitter terminal of the transistor.

The micro Pt heater, because of its small heat capacity, could be heated up in a very short time, leading to a very fast change of $R_{\mathrm{h}}$ and $V_{\mathrm{T}}$. To record the transient variation of the voltage signal, a $100 \mathrm{MHz}$ high-speed digitizer (NI 5112, National Instruments) was employed. Because of the expected small change in the Pt heater's resistance during the pulse-heating period, the voltage signal $V_{\mathrm{T}}$ was expected to have a small dynamic variation on a relatively large base voltage. However, for the small measurement range of the input voltage signals ( $50-500 \mathrm{mV}$ ), NI 5112 can only provide a maximum offset of $\pm 500 \mathrm{mV}$. To make full use of the 8-bit resolution of the NI 5112, a low noise and high-speed precision operational amplifier (LT1007 CN8, Linear Technology) was used to provide an additional voltage offset before inputting $V_{\mathrm{T}}$ to the NI 5112, as shown in the dotted-line frame in figure $2(b)$. The values of the resistors and capacitor used in the experiment are also labeled in the figure.

Note that the analog trigger port of NI 5112 was also connected to one of the $8255 \mathrm{I} / \mathrm{O}$ card output ports, so that the temperature measurement process was synchronized with the rising edge of the heating pulse. It is also pertinent to note that the voltage 'spike' at the beginning and end of the switching was not serious in the experiment because the typical operation frequency was less than $1 \mathrm{kHz}$ (the typical heating pulse width was $1.66 \mathrm{~ms}$ ). Although the spikes would still alter the signal form at the on/off moment to a certain degree, the addition of the capacitor $C$ (figure $2(b)$ ) reduced this switching artifact to an acceptable level.

\subsubsection{Calibration of the resistance-temperature curve.}

To ensure highly accurate temperature measurements, the relationship between electric resistance and temperature of the micro Pt heater must be known, and this relationship must be stable and repeatable. For a positive-temperature-coefficient resistance temperature sensor, the resistance of the Pt resistor as a function of temperature can be expressed as

$$
R=R_{0}\left[1+\alpha\left(T-T_{0}\right)\right]
$$

where $R$ is the resistance of the Pt resistor at temperature $T, R_{0}$ is the resistance at a reference temperature $T_{0}$ and $\alpha$ is the temperature coefficient of the Pt resistor. Before the temperature measurements, we need to calibrate the $\mathrm{Pt}$ heater to obtain an accurate value of $\alpha$. As mentioned before, due to the small size of the Pt heater, its resistance change over the temperature range of interest was expected to be small. To improve the accuracy of calibration and to facilitate the

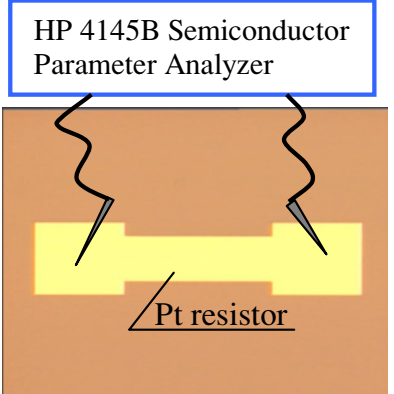

Figure 3. Picture of the large Pt resistor for temperature coefficient calibration, which was fabricated in an identical manner to that of the micro Pt heater.

handling process, we used a larger Pt resistor for the calibration process, as shown in figure 3. This large calibration resistor was fabricated in an identical manner to the Pt heater used for bubble generation in the present experiment. The only difference was that it was larger: $300 \mu \mathrm{m}$ in length and $100 \mu \mathrm{m}$ in width.

To start calibration, the chip of the calibration Pt resistor was placed on a S-1060 vacuum hot-chuck of a probe station (Signatone), whose temperature was controlled by a 'QuieTemp' hot-chuck controller (Signatone's S-1060). Two probe tips were in firm contact with the pad of the Pt calibration resistor (as shown in figure 3 ), and they were conducted to the input ports of a HP 4145B Semiconductor Parameter Analyzer. During calibration, the temperature of the chuck surface was first increased to the desired value, which covered a range from room temperature $(295 \mathrm{~K})$ to about $500 \mathrm{~K}$. When the temperature of the chuck surface was stabilized, a gradually increased voltage in controlled steps was then imposed on the Pt calibration resistor by the HP 4145B Semiconductor Parameter Analyzer, and the corresponding current at each voltage was recorded. Thus, the resistance of the Pt calibration resistor at each tested temperature could be calculated by a linear fitting of the voltage-current data points. Figure 4(a) shows the voltage-current curve of the Pt calibration resistor at a temperature of $388 \mathrm{~K}$, while figure $4(b)$ shows the resistance of the Pt calibration resistor as a function of temperature. No hysteresis effect was observed in the repeated calibration process. A linear fitting of the data points in figure $4(b)$ indicates that the resistance-temperature relationship of the Pt calibration resistor can be expressed as

$$
R=0.56787+0.02769 T
$$

where $R$ is in Ohms and $T$ is in Kelvins. Equation (3) can also be expressed in the form of equation (2) to give

$$
R=8.7364[1+0.00317(T-295)]
$$

where a reference temperature $T_{0}=295 \mathrm{~K}$ (room temperature) has been chosen. Comparing equations (2) and (4), we can obtain the temperature coefficient $\alpha=0.00317 \mathrm{~K}^{-1}$. Since the $\mathrm{Pt}$ calibration resistor and the Pt micro heater were fabricated in an identical manner, it is assumed that the temperature coefficient of the Pt micro heater was also $0.00317 \mathrm{~K}^{-1}$.

As shown in figure $1(b)$, the total resistance of the $\mathrm{Au}$ electric pad and the Pt micro heater can be expressed as

$$
R_{\mathrm{h}}=R_{\mathrm{Au}}+R_{\text {cont }}+R^{\prime}+R_{\text {slim }}
$$




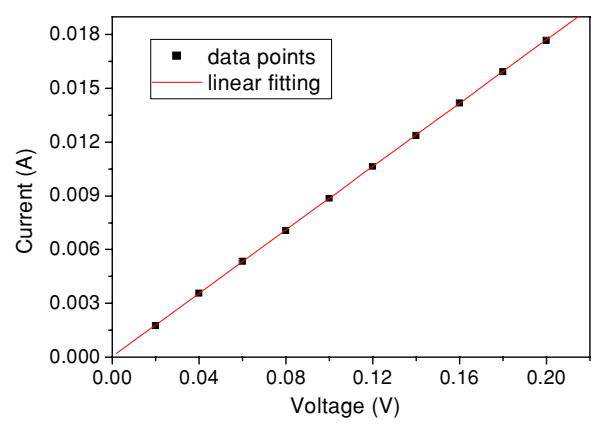

(a)

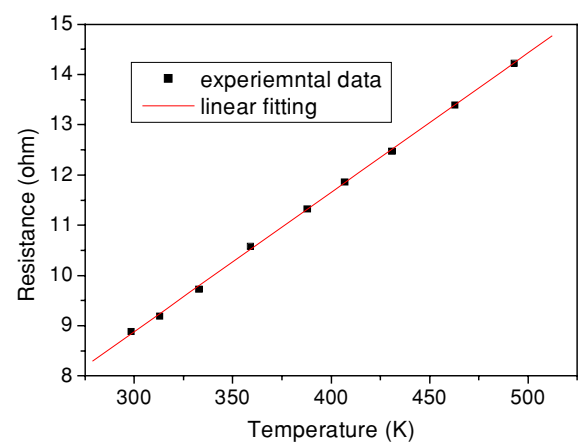

(b)

Figure 4. Calibration curve of the Pt calibration resistor: (a) voltage-current curve at $388 \mathrm{~K}$ and $(b)$ resistance versus temperature.

where $R_{\mathrm{Au}}$ is the resistance of the Au electric pad, $R_{\text {cont }}$ is the contact resistance of $\mathrm{Au}$ and $\mathrm{Pt}$ film, $R^{\prime}$ is the resistance of the 'wide' part of the non-uniform-width Pt micro heater and $R_{\text {slim }}$ is the resistance of the 'slim' part. In our previous study [8], we have investigated the temperature distribution of another non-uniform-width micro Pt heater, whose dimensions were the same as those of the present one except that the width of its slim part was $3 \mu \mathrm{m}$ (as compared to $2 \mu \mathrm{m}$ for the present one), and its thickness was $1000 \AA$ (as compared to $1500 \AA$ for the present one). In that study, we found that this kind of micro heater could realize a highly localized heating just at the slim part of the heater, while most of the other parts of the heater could still be at ambient temperature. Furthermore, this highly localized heating directly resulted in a single bubble generation exactly at the slim part of the heater. Therefore, we assume that only the resistance of the slim part of the Pt micro heater is temperature dependent. Thus, equation (5) becomes

$$
R_{\mathrm{h}}=R_{\mathrm{Au}}+R_{\mathrm{cont}}+R^{\prime}+R_{\mathrm{sref}}\left[1+\alpha\left(T-T_{0}\right)\right]
$$

where $R_{\text {sref }}$ is the resistance of the slim part at a reference temperature $T_{0}, \alpha$ is the temperature coefficient and $T$ is the temperature of the slim part of the Pt micro heater. Also, we have

$$
R_{\text {sref }}=R_{\text {sheet }}\left(\frac{L_{\mathrm{s}}}{W_{\mathrm{s}}}\right)
$$

and

$$
R^{\prime}=R_{\text {sheet }}\left(\frac{L^{\prime}}{W^{\prime}}\right)
$$

where $R_{\text {sheet }}$ is the sheet resistance of the Pt micro heater, which is $1.64 \Omega$ for the present case; $L_{\mathrm{s}}$ and $W_{\mathrm{s}}$ are the length and width of the slim part and $L^{\prime}$ and $W^{\prime}$ are those of the wide part. Inserting equation (7) into equation (6), we obtain

$$
\begin{aligned}
R_{\mathrm{h}}= & R_{\mathrm{Au}}+R_{\text {cont }}+R_{\text {sheet }}\left(\frac{L^{\prime}}{W^{\prime}}\right) \\
& +R_{\text {sheet }}\left(\frac{L_{\mathrm{s}}}{W_{\mathrm{s}}}\right)\left[1+\alpha\left(T-T_{0}\right)\right] .
\end{aligned}
$$

In the present experiment, the terms $R_{\mathrm{Au}}+R_{\text {cont }}$ on the righthand side (RHS) of equation (8) were obtained by measuring the total resistance $R_{\mathrm{h}}$ at room temperature using a multimeter, while the last two terms on the RHS of equation (8) were calculated on the basis of the measured heater dimensions and sheet resistance. Combining equations (1) and (8), a relationship between $V_{\mathrm{T}}$ and $T$ can be expressed as

$$
\begin{aligned}
V_{\mathrm{T}}= & \left\{\left(V_{\mathrm{cc}}-V_{\mathrm{ce}}\right) /\left(R_{\mathrm{Au}}+R_{\text {cont }}+R_{\text {sheet }}\left(L^{\prime} / W^{\prime}\right)\right.\right. \\
& \left.\left.+R_{\text {sheet }}\left(L_{\mathrm{s}} / W_{\mathrm{s}}\right)\left[1+\alpha\left(T-T_{0}\right)\right]+R_{\mathrm{T}}\right)\right\} R_{\mathrm{T}}+V_{\text {ce }}
\end{aligned}
$$

Thus, by recording the change of $V_{\mathrm{T}}$ and $V_{\mathrm{ce}}$ during the pulse-heating period, the temporal variation of the average temperature of the Pt micro heater, $T$, could be calculated from equation (9).

\subsection{DNA sample preparation}

The DNA specimens were the same as that used in the previous experiments by Deng et al [10] for studying the micro bubble dynamics in ssDNA solutions. A 60-base synthetic oligonucleotide was diluted into four concentrations: $0.1,1$, 6.4 and $10 \mu \mathrm{g} \mu \mathrm{l}^{-1}$ for use in the present experiment on micro bubble generation and bubble nucleation temperature measurements.

\section{A transient 3D heat conduction model}

Although the temperature of the heater could be obtained by using the micro Pt heater as a self-sensing temperature sensor, the temperature distribution in the ssDNA solution was still unknown when the thermal bubble was generated during the experiment. This information is important in view of the fact that the structure and stability of DNA molecules are very temperature sensitive [17]. Furthermore, the determination of the size of the superheated region in the DNA solution when the thermal bubble was formed is helpful for the evaluation of the possible damage region to DNA.

To reveal the temperature distribution in the solution adjacent to the micro heater just before the bubble nucleation process, a transient $3 \mathrm{D}$ heat conduction model was used. The governing equation for transient $3 \mathrm{D}$ heat conduction with inner heat source is

$$
\rho c_{\mathrm{p}} \frac{\partial T}{\partial t}=k\left(\frac{\partial^{2} T}{\partial x^{2}}+\frac{\partial^{2} T}{\partial y^{2}}+\frac{\partial^{2} T}{\partial z^{2}}\right)+\Phi
$$

where $T, \rho, c_{\mathrm{p}}, k$ and $\Phi$ are the temperature, density, isobaric heat capacity, thermal conductivity and the inner heat source per unit volume, respectively. A detailed description of the numerical model is found elsewhere [8]. Some material properties used in the model are listed in table 1. Since the exact thermal properties of the ssDNA are not available, properties of water were chosen instead for the numerical simulation. Note that the measured temperature of the micro 
Measurements of micro bubble nucleation temperatures in DNA solutions

Table 1. Material properties.

\begin{tabular}{lccc}
\hline & $\begin{array}{l}\text { Thermal } \\
\text { conductivity } \\
(k)\left(\mathrm{W} \mathrm{m} \mathrm{m}^{-1}{ }^{\circ} \mathrm{C}^{-1}\right)\end{array}$ & $\begin{array}{l}\text { Heat capacity } \\
\left(c_{\mathrm{p}}\right)\left(\mathrm{J} \mathrm{kg}^{\circ} \mathrm{C}^{-1}\right)\end{array}$ & $\begin{array}{l}\text { Density }(\rho) \\
\left(\mathrm{kg} \mathrm{m}^{-3}\right)\end{array}$ \\
\hline Silicon oxide & 1.4 & 840 & 2070 \\
Silicon nitride & 1.67 & 714 & 3200 \\
Platinum & 73 & 133.1 & 21500 \\
Gold & 315 & 128.7 & 19280 \\
Parylene N & 0.12 & 1300 & 1110 \\
Water & 0.609 & 4180 & 1000 \\
\hline
\end{tabular}

heater was actually an average temperature. Thus, for a proper comparison of experimental data and numerical results, we define a spatial-average temperature for the slim part of the micro heater as follows:

$$
\bar{T}=\frac{1}{V_{\text {slim }}} \oint T(x, y, z) \mathrm{d} x \mathrm{~d} y \mathrm{~d} z
$$

where $V_{\text {slim }}$ is the volume of the slim part of the heater.

\section{Results and discussion}

After loading the ssDNA sample onto the micro bubble actuator chip, a typical $1.66 \mathrm{~ms}$-width voltage was imposed on the serial connection of the micro Pt heater and the constant resistance resistor $R_{\mathrm{T}}$. Starting from zero, the input voltage $V_{\mathrm{cc}}$ was gradually increased until bubbles appeared in the DNA solution, which was called 'onset bubble nucleation'. The method to calculate the power input to the micro heater was discussed in detail elsewhere [10]. Note that the power input was calculated on the basis of the resistance of the micro heater at room temperature, and it could change as the resistance increased with temperature during the pulse-heating period. The temperature measurement of the heater was computed according to equation (9) from the recorded data of $V_{\mathrm{cc}}$ and $V_{\text {ce }}$ using a $100-\mathrm{MHz}$ high-speed digitizer. The temperature measurements were synchronized with the heating process.

\subsection{Onset bubble nucleation temperature in ssDNA}

4.1.1. Measurements in $1 \mu g \mu l^{-1}$ ssDNA. Curve I in figure 5 shows temporal surface temperature measurements of the micro heater in the $1 \mu \mathrm{g} \mu \mathrm{l}^{-1}$ ssDNA solution for the case without bubble generation where the power input was $11.1 \mathrm{~mW}$ (which is less than the requirement for the onset of bubble nucleation) during a typical $1.66 \mathrm{~ms}$-width heating pulse. It is shown that at the initial stage after the beginning of the pulse heating, the average temperature of the heater increased exponentially with time until about $450 \mathrm{~K}$, indicating a lumped capacitance characteristic of the micro heater in less than $20 \mu \mathrm{s}$. Then, the heater temperature measurements continue to increase slowly due to pure heat conduction without bubble nucleation.

Curve II in figure 5 shows the measured average temperature variation of the heater with respect to time for onset bubble nucleation in the $1 \mu \mathrm{g} \mu \mathrm{l}^{-1}$ ssDNA solution with power input of $13.8 \mathrm{~mW}$, which corresponded to the heat flux at the heater surface (rate of heat generation in the heater) at $33.01 \mathrm{MW} \mathrm{m}^{-2}$. Since the bubble generation process was very stable and repeatable, there was no noticeable change of the

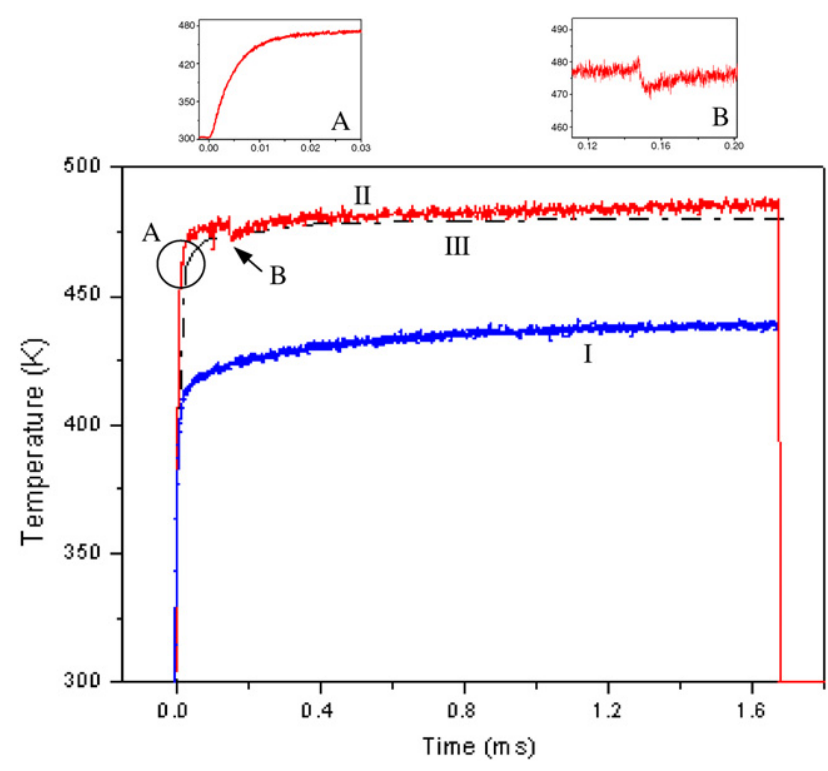

Figure 5. Measured average temperature of the micro heater as a function of time. Curve I: no bubble generation in $1 \mu \mathrm{g} \mu \mathrm{l}^{-1}$ ssDNA, input power $11.1 \mathrm{~mW}$. Curve II: onset bubble nucleation in $1 \mu \mathrm{g} \mu \mathrm{l}^{-1}$ ssDNA, input power $13.8 \mathrm{~mW}$. Curve III: numerical results, input power $13.8 \mathrm{~mW}$.

temperature-time curve during the repeated pulses. As shown in curve II, at the initial stage after the beginning of the pulse heating, the average temperature of the heater also increased exponentially with time (refer to the inset A). The temperature increased from room temperature to $465 \mathrm{~K}$ in less than $20 \mu \mathrm{s}$ corresponding to a heating rate of $8.6 \times 10^{6} \mathrm{~K} \mathrm{~s}^{-1}$. Note that this heating rate was very similar to the experiment performed by Skripov [18], who showed that a heating rate as high as $6 \times$ $10^{6} \mathrm{~K} \mathrm{~s}^{-1}$ was required for homogeneous nucleation around a platinum heating wire. After reaching its maximum (480 K), the temperature increase curve experienced a ' $\mathrm{V}$ ' shape change: it suddenly dropped from 480 to $470 \mathrm{~K}$ and then slowly increased to $486 \mathrm{~K}$ at the end of the heating pulse (refer to $\mathrm{B}$ in figure 5), which made the temperature change of the micro heater discontinuous. A similar temperature change was also observed by Tsai and Lin [15] in their study on transient bubble nucleation in isopropyl alcohol on a polysilicon micro heater $\left(95 \times 10 \mu \mathrm{m}^{2}\right)$ when a medium input current was employed.

We speculate that the ' $\mathrm{V}$ ' shape temperature change in curve II, occurring at $150 \mu$ s after the beginning of the heating pulse, is an indication of the beginning of bubble nucleation. Before bubble nucleation, the heat supplied by the heater was used to heat up the heater itself, the silicon nitride and oxide layer underneath the heater and the ssDNA solution immediately adjacent to the heater by conduction heat transfer. During this period, the temperature of the heater increased exponentially indicating a lumped capacitance heat conduction characteristics as shown during the initial time of curve II. As the surrounding ssDNA solution was heated up to the incipient bubble nucleation temperature, a highly localized near homogeneous boiling occurred in the ssDNA solution adjacent to the heater. Compared with the case before bubble nucleation, a relatively large amount of heat was absorbed from the heater during this period to meet the requirement 
of the evaporization latent heat of the solvent. This could result in a sudden drop of the heater temperature, as shown in the inset B of figure 5, if the power input to the heater was not large enough to cover that evaporization latent heat. Therefore, at a heating rate of $8.6 \times 10^{6} \mathrm{~K} \mathrm{~s}^{-1}$, the onset bubble nucleation temperature in the $1 \mu \mathrm{g} \mu \mathrm{l}^{-1}$ ssDNA solution could be identified at $480 \mathrm{~K}$, and the bubble nucleation occurred at approximately $150 \mu$ s after the beginning of a $1.66 \mathrm{~ms}$-width pulse heating.

Curve III in figure 5 is the numerical result of the spatialaverage temperature of water adjacent to the heater based on transient heat conduction with the power input of $13.8 \mathrm{~mW}$, the same as that of curve II. Generally, the numerical result of the spatial-averaged heater temperature variation is very close to measurements. Except near the ' $\mathrm{V}$ ' shape temperature change, the temperature of the heater given by curve II is similar to curve III with a temperature difference less than $10 \mathrm{~K}$ at all times. However, the numerical results of the temperature curve based on the heat conduction model did not change much after its exponential increase at the initial stage, while temperature measurements showed a ' $\mathrm{V}$ ' shape change after its exponential increase and a slow yet continuous increase after bubble nucleation. This discrepancy is due to the fact that the heat conduction model fails to take into consideration the phase change process as well as the change of the boundary condition after that.

The transient heat conduction model can be used to estimate the superheated region in the ssDNA solution just before bubble nucleation, which could be a quantitative reference for evaluating the possible damage region to the DNA molecules due to the thermal bubble generation. As mentioned earlier, because of the lack of data on ssDNA's physical properties, water was chosen as the test liquid in the numerical model. Figure $6(a)$ shows the numerical result of the temperature contours in the water adjacent to the micro heater at $150 \mu \mathrm{s}$, which is the speculated moment for the onset of bubble nucleation in the $1 \mu \mathrm{g} \mu \mathrm{l}^{-1}$ ssDNA solution. The power input to the heater in the computation was $13.8 \mathrm{~mW}$, the same as that required for the onset of bubble nucleation in the ssDNA solution. As shown in the figure, the micro heater generated a highly localized superheated $(T>373 \mathrm{~K})$ area of $12 \times 2.5 \mu \mathrm{m}^{2}$, which was comparable to the size of the slim part of the non-uniform-width micro heater $(10 \times$ $\left.2 \mu \mathrm{m}^{2}\right)$. This is consistent with our previous assumption in section 2.2.2 that only the slim part of the heater would be heated up to a high temperature to induce bubble nucleation. Figure 6(b) shows the numerical results of the transient spatialaverage temperature of the water adjacent to the top of the slim part of the heater. It indicates that the temperature decays exponentially away from the heater surface to the liquid, and the superheated liquid layer just before bubble nucleation was about $2.1 \mu \mathrm{m}$ above the heater. Based on figures $6(a)$ and (b), the estimated superheated liquid region just before bubble nucleation is approximately $12 \times 2.5 \times 2.1 \mu \mathrm{m}^{3}$ above the slim part of the micro heater.

4.1.2. DNA concentration effects on bubble nucleation temperature. In our previous study [10], we have investigated the micro bubble generation and its subsequent bubble dynamics using four different concentrations $(0.4,1$,

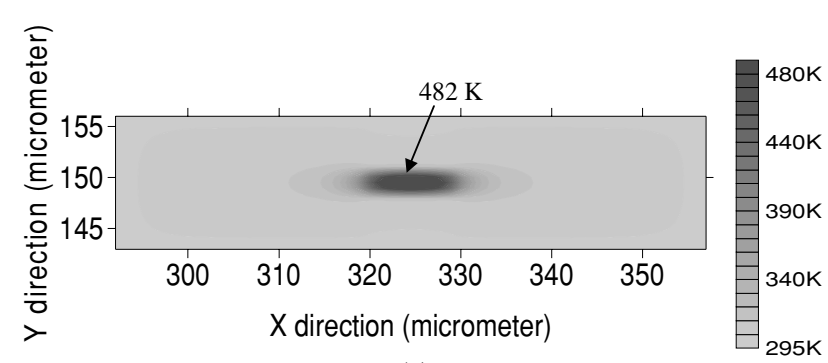

(a)

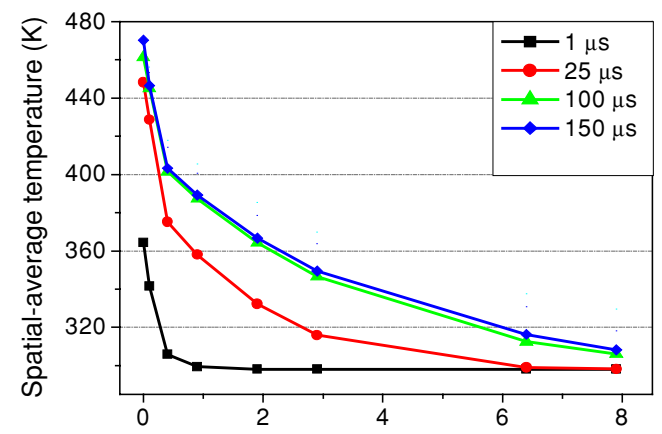

Vertical direction from the Parylene surface into the water $(\mu \mathrm{m})$

(b)

Figure 6. Numerical results of temperature distribution. The input power to the micro heater was $13.8 \mathrm{~mW}$. (a) Temperature distribution of the water on top of the heater surface at the moment just before bubble nucleation (150 $\mu$ s after the beginning of the heating pulse) and $(b)$ transient spatial-average temperature at different depths in water.

6.4 and $\left.10 \mu \mathrm{g} \mu \mathrm{l}^{-1}\right)$. We observed that the bubble growth period (about $0.5 \mathrm{~ms}$ ) at high concentrations (6.4 and $10 \mu \mathrm{g} \mu \mathrm{l}^{-1}$ ) was much shorter in comparison with the heating pulse width $(1.66 \mathrm{~ms})$, while the bubble growth period at low and medium concentrations $\left(0.4\right.$ and $\left.1 \mu \mathrm{g} \mu 1^{-1}\right)$ was comparable to the heating pulse width. This means that at high concentrations, the bubble began to collapse even though the heating from the micro heater was still going on.

In section 4.1.1, we have already discussed bubble nucleation temperature in the $1 \mu \mathrm{g} \mu \mathrm{l}^{-1}$ ssDNA solution. To reveal the DNA concentration effect on bubble nucleation temperature, we also measured the transient average temperature variation of the heater for onset bubble nucleation in three other concentrations: $0.4,6.4$ and $10 \mu \mathrm{g} \mu \mathrm{l}^{-1}$, while the heating pulse width was kept at $1.66 \mathrm{~ms}$.

Figure 7 shows the effect of concentration on temporal temperature variations of the heater in ssDNA solutions. In this graph, curves I, II, III and IV correspond to the cases of onset bubble nucleation in $0.4 \mu \mathrm{g} \mu \mathrm{l}^{-1}$ ssDNA, $1 \mu \mathrm{g} \mu \mathrm{l}^{-1}$ ssDNA, $6.4 \mu \mathrm{g} \mu \mathrm{l}^{-1}$ and $10 \mu \mathrm{g} \mu \mathrm{l}^{-1}$ ssDNA, respectively. The ' $\mathrm{V}$ ' shape temperature change was observed for all four cases as shown in the insets $\mathrm{A}$ and $\mathrm{B}$, indicating the beginning of bubble nucleation.

It is very interesting to examine the temperature variation curves in figure 7 with what we have learned about bubble dynamic behavior from our previous study [10], although the temperature is that of the heater not the vapor in the bubble. From figure 5(b) in [10], we know that at high DNA concentrations, the bubble began to shrink on the slim part of the micro heater at around $0.5 \mathrm{~ms}$ even though the heating 


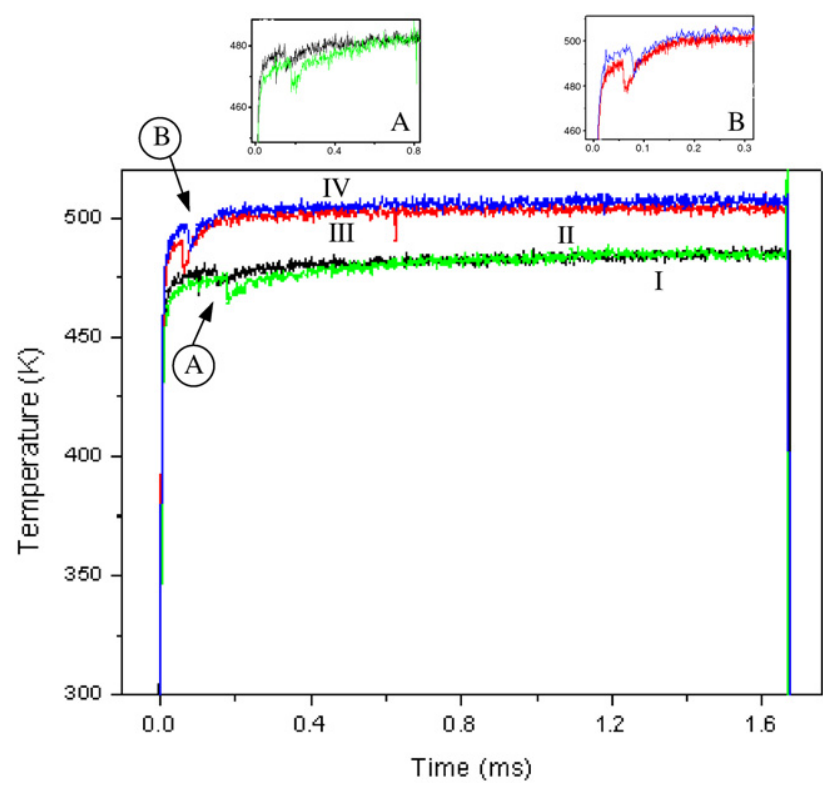

Figure 7. Measured average temperature of the micro heater as a function of time for onset bubble nucleation in four ssDNA concentrations. Curve I: $0.4 \mu \mathrm{g} \mu \mathrm{l}^{-1}$, input power $13.4 \mathrm{~mW}$. Curve II: $1 \mu \mathrm{g} \mu \mathrm{l}^{-1}$, input power $13.8 \mathrm{~mW}$. Curve III: $6.4 \mu \mathrm{g} \mu \mathrm{l}^{-1}$, input power $14.9 \mathrm{~mW}$. Curve IV: $10 \mu \mathrm{g} \mu \mathrm{l}^{-1}$, input power $15.3 \mathrm{~mW}$.

pulse width was $1.66 \mathrm{~ms}$, and the bubble diameter at $0.5 \mathrm{~ms}$ was smaller than that at low and medium concentrations. Therefore, at high concentrations the slim part of the heater will be in contact with more liquid on top of it after the beginning of bubble nucleation in comparison with those of low and medium concentrations. On the other hand, at low and medium concentrations the slim part of the heater will be in contact with more vapor on top of it after the beginning of bubble nucleation because the bubble kept on growing.

Note that the thermal conductivity of the vapor phase is much lower than that of the liquid phase. For example, at atmospheric pressure, the thermal conductivity of the saturated water vapor is only $5 \%$ of that of water. Thus, after bubble nucleation, more heat was absorbed from the micro heater for the cases of high DNA concentrations due to the enlarged contact area of the slim part of the micro heater with the liquid phase, which has a relatively large thermal conductivity. This resulted in a smaller temperature increase of the micro heater after bubble nucleation. For example, the temperature increase of the micro heater from 0.5 to $1.66 \mathrm{~ms}$ was around $1 \mathrm{~K}$ as shown in curves III and IV (at high concentrations) in figure 7. On the other hand, for the cases of low and medium concentrations, less heat was absorbed from the micro heater after bubble nucleation due to the enlarged contact area of the micro heater with the vapor phase, which has a low thermal conductivity. This resulted in the relatively large temperature increase of the micro heater after bubble nucleation. As shown in curves I and II in figure 7, the temperature increase of the micro heater from 0.5 to $1.66 \mathrm{~ms}$ was around $5 \mathrm{~K}$, which was larger than that of $1 \mathrm{~K}$ at high DNA concentrations.

The data of the onset bubble nucleation temperature at each DNA concentration given in figure 7 are re-plotted in figure 8. The power input required for the onset of bubble nucleation is also presented in the same graph. Generally, the

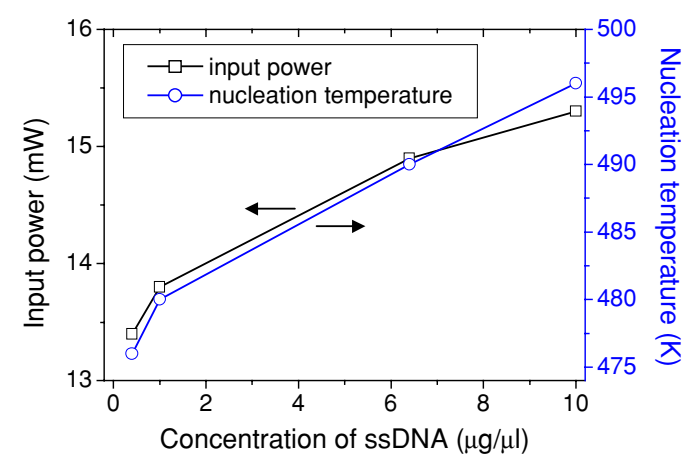

Figure 8. Input power and bubble nucleation temperature at four DNA concentrations.

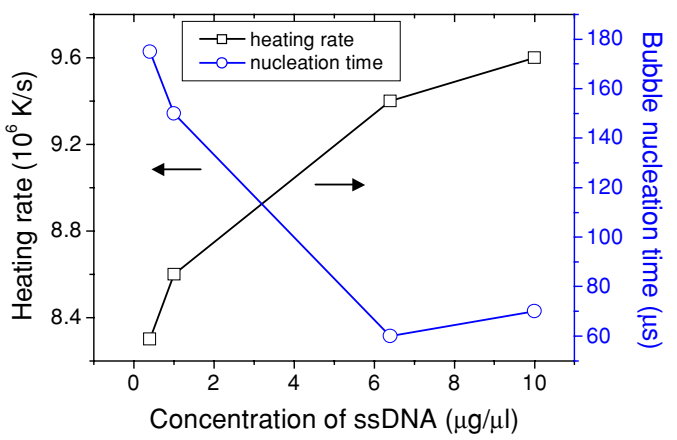

Figure 9. Heating rate and bubble nucleation time at four DNA concentrations.

bubble nucleation temperature increased with the increase of DNA concentration, which is due to the fact that the power input for the onset of bubble nucleation increased with the concentration as shown in the figure. Note that the DNA concentration effect on bubble nucleation was investigated in our previous study [10].

Figure 9 shows the heating rate (temperature increase rate of the micro heater) and the bubble nucleation time (the time of the occurrence of bubble nucleation after the beginning of the heating pulse) at the four DNA concentrations. It is shown that the heating rate increased with the concentration. For example, the heating rate at $0.4 \mu \mathrm{g} \mu \mathrm{l}^{-1}$ was $8.3 \times 10^{6} \mathrm{~K} \mathrm{~s}^{-1}$, while it was $9.6 \times 10^{6} \mathrm{~K} \mathrm{~s}^{-1}$ at $10 \mu \mathrm{g} \mu \mathrm{l}^{-1}$, indicating an increase of $15 \%$. Owing to a faster temperature increase, the bubble nucleation time at high concentrations was shorter than that at low concentrations. For example, the bubble nucleation time was $175 \mu \mathrm{s}$ at a concentration of $0.4 \mu \mathrm{g} \mu \mathrm{l}^{-1}$, while it was $70 \mu \mathrm{s}$ at a concentration of $10 \mu \mathrm{g} \mu \mathrm{l}^{-1}$.

\subsection{Bubble nucleation temperature under large input power}

In addition to measurements on the onset bubble nucleation at a power input of $13.8 \mathrm{~mW}$ as discussed in the previous section, we also measured the average temperature of the heater under a larger power input of $16.3 \mathrm{~mW}$ to the micro heater (corresponding to a heat flux of $38.66 \mathrm{MW} \mathrm{m}^{-2}$ ) for bubble nucleation in $1 \mu \mathrm{g} \mu \mathrm{l}^{-1} \mathrm{ssDNA}$, while the pulse-heating width was kept at $1.66 \mathrm{~ms}$. For comparison, the results from both measurements are shown in figure 10 .

As shown in curve I, under a larger power input the temperature of the heater increased much faster at the initial 
Table 2. Thermal characteristics of bubble nucleation in ssDNA solution on a micro Pt heater (feature size $10 \times 2 \mu \mathrm{m}^{2}$ ) subject to a $1.66 \mathrm{~ms}$-wide heating pulse.

\begin{tabular}{|c|c|c|c|c|c|c|}
\hline \multirow[b]{2}{*}{$\begin{array}{l}\text { DNA concentration } \\
\left(\mu \mathrm{g} \mu \mathrm{l}^{-1}\right)\end{array}$} & \multicolumn{6}{|c|}{ Thermal quantities } \\
\hline & $\begin{array}{l}\text { Input power } \\
(\mathrm{mW})\end{array}$ & $\begin{array}{l}\text { Heat flux } \\
\left(\mathrm{MW} \mathrm{m}^{-2} \text { ) }\right.\end{array}$ & $\begin{array}{l}\text { Heating } \\
\text { rate }\left(\mathrm{K} \mathrm{s}^{-1}\right)\end{array}$ & $\begin{array}{l}\text { Nucleation } \\
\text { time }(\mu \mathrm{s})\end{array}$ & $\begin{array}{l}\text { Nucleation } \\
\text { temperature (K) }\end{array}$ & $\begin{array}{l}\text { Superheated region } \\
\left(\mathrm{L} \times \mathrm{W} \times \mathrm{H} \mu \mathrm{m}^{3}\right)\end{array}$ \\
\hline 0.4 & 13.4 & 31.96 & $8.3 \times 10^{6}$ & 175 & 476 & $12 \times 2.5 \times 2.1$ \\
\hline 1 & 13.8 & 33.01 & $8.6 \times 10^{6}$ & 150 & 480 & $12 \times 2.5 \times 2.1$ \\
\hline 6.4 & 14.9 & 35.34 & $9.4 \times 10^{6}$ & 60 & 490 & $13 \times 2.5 \times 2.1$ \\
\hline 10 & 15.3 & 36.33 & $9.6 \times 10^{6}$ & 70 & 496 & $13 \times 2.5 \times 2.3$ \\
\hline 1 & 16.3 & 38.66 & $1.1 \times 10^{7}$ & 60 & 520 & $13 \times 2.5 \times 2.5$ \\
\hline
\end{tabular}

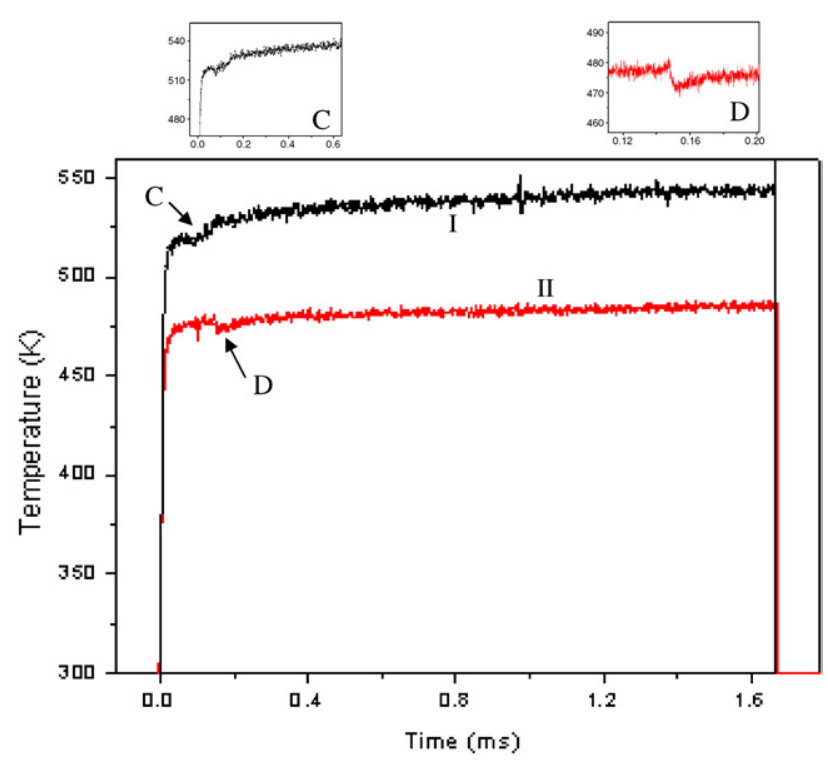

Figure 10. Measured average temperature variation of the heater during bubble nucleation in $1 \mu \mathrm{g} \mu \mathrm{l}^{-1}$ ssDNA solution. Curve I: larger input power: $16.3 \mathrm{~mW}$. Curve II: onset bubble generation, input power: $13.8 \mathrm{~mW}$.

stage: from room temperature to $510 \mathrm{~K}$ in less than $20 \mu \mathrm{s}$, indicating a heating rate of $1.1 \times 10^{7} \mathrm{~K} \mathrm{~s}^{-1}$. A ' $\mathrm{V}$ ' shape temperature change at $520 \mathrm{~K}$ was also observed in this case as shown in the inset $C$ of figure 10 , which occurred at about $60 \mu \mathrm{s}$ after the beginning of the heating pulse. The bubble nucleation temperature of $520 \mathrm{~K}$ was higher than the previously measured $480 \mathrm{~K}$ for the onset bubble nucleation. As shown in the inset $\mathrm{C}$, there was no noticeable temperature drop of the heater during the ' $\mathrm{V}$ ' shape change as bubble nucleation occurred, which is different from the previous case of onset bubble nucleation (refer to inset D in figure 10). This discrepancy can be attributed to the increased power input in this case compared with the 'onset' case. A large power input also resulted in a distinct increase of the heater temperature after bubble nucleation (see curve I) compared with that for the onset bubble nucleation (curve II). Figure 10 also shows that the increase of the power input promotes the early occurrence of bubble nucleation.

Figure 11 shows the numerical results of temperature contours in the water adjacent to the micro heater just before bubble nucleation at a high heat flux of $16.3 \mathrm{~mW}$. From the numerical results, the size $(\mathrm{L} \times \mathrm{W} \times \mathrm{H})$ of the superheated region just before the bubble nucleation was found to be $13 \times$

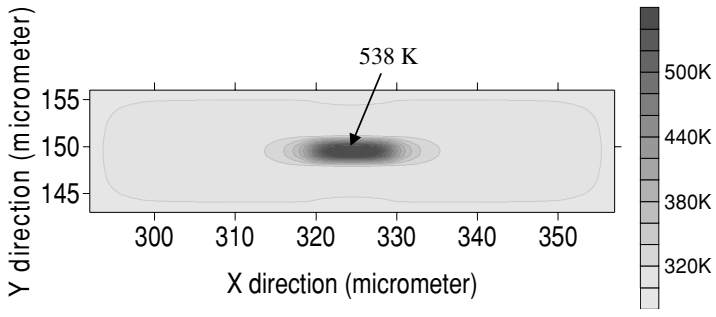

Figure 11. Numerical results of temperature distribution of the water on top of the heater surface for a larger input power $(16.3 \mathrm{~mW})$ at $60 \mu \mathrm{s}$ after the pulse-heating process.

$2.5 \times 2.5 \mu \mathrm{m}^{3}$, which is still comparable to the feature size of the micro Pt heater $\left(10 \times 2 \mu \mathrm{m}^{2}\right)$.

Table 2 summarizes the thermal characteristics of bubble nucleation in the ssDNA solution at four different concentrations. Obviously, a higher heat flux supplied by the heater could result in a higher heating rate, a faster bubble nucleation process at a higher nucleation temperature. For all cases under consideration, however, the superheated regions in the fluid at the moment just before bubble nucleation are comparable to the feature size of the micro heater (the size of the slim part of the heater). This is due to the low thermal diffusivity of the DNA aqueous solution.

It is pertinent to note that research on transient boiling has been previously studied for heaters of thin film or wire type [12-15, 18-23]. In most of these studies, the feature size of the heater was at a scale of $100 \mu \mathrm{m}$, and the heating pulse was as short as several microseconds. For a microsecond-width pulse heating, a very high heating rate was required in order to raise the temperature of the heater to a nucleation temperature before the end of the heating process. In this situation, usually a high power input was imposed on the heater and a high nucleation temperature could be measured. Avedisian et al [12] summarized previous measurements on the bubble nucleation temperature of water from various researchers, and showed that the bubble nucleation temperature could be as high as $550 \mathrm{~K}$ and the heating rate was of the order of $10^{7}$ $10^{8} \mathrm{~K} \mathrm{~s}^{-1}$, which were larger than those obtained in the present experiment. The generation of a single bubble in the present experiment can be attributed to a highly localized near-homogeneous boiling mechanism, which is due to the fact that the non-uniform-width heater can only heat up the fluid surrounding it. For a detailed description of this kind of boiling, the reader is referred to our previous paper [8]. 


\subsection{Error analysis}

Although the micro Pt heater has a good linearity and repeatability of the resistance versus temperature curve, its small resistance and small temperature coefficient make the temperature measurement sensitive to the noise signal of the electric circuit. Temperature measurements in this experiment have uncertainties due to these noise signals, which may stem from the power supply, and the operation of the transistor or operational amplifier, especially at the switching moments of the pulse-heating process.

In the temperature range of the present experiment, the average voltage change $\left(V_{\mathrm{T}}\right)$ due to the temperature change of the heater was about $0.4 \mathrm{mV} \mathrm{K}^{-1}$ according to equation (9). The highest voltage resolution of the 8-bit data acquisition card (NI 5112 high-speed digitizer) was $0.336 \mathrm{mV}$, corresponding to a temperature resolution of $1 \mathrm{~K}$ in the experiment. Another source of error is the inaccuracy of the determination of the temperature coefficient of the micro Pt heater, which is due to the non-uniformity of the $\mathrm{Pt}$ sputtering process for the micro heater and the calibration resistor. The inaccurate measurement of the heater size is also another source of error.

Error of temperature measurements also comes from the assumption that only the resistance of the slim part of the micro heater was a function of temperature, which would make the measurement somewhat larger than the real value. This error was quantitatively estimated using the following method: first, the 3D heat conduction simulation showed that the spatialaveraged temperature increase of the 'wide' part of the micro heater was about $7 \mathrm{~K}$, which could lead to an increase in $R^{\prime}$ (refer to equations (5) and (7b)). Secondly, with this new $R^{\prime}$ and equation (9), a new temperature of the Pt micro heater was obtained. Finally, using the new temperature and the original one, it was found that the experimental error due to the assumption that 'only the resistance of the slim part of the micro heater was a function of temperature' was about $3 \%$.

\section{Concluding remarks}

In this paper, we have investigated micro thermal bubble nucleation in ssDNA solutions by a micro bubble actuator with particular emphasis on measurements of the bubble nucleation temperature at different DNA concentrations, and the determination of the superheated region above the heater just before bubble nucleation. A ' $V$ ' shape temperature change of the micro heater during the pulse-heating process was observed only for the cases where bubble nucleation occurred, which has been speculated to be an indication of the beginning of the bubble nucleation. It was observed that an increase in the DNA concentration or a higher heat flux from the heater could lead to a higher heating rate, a faster bubble nucleation process and a higher nucleation temperature. Based on a transient $3 \mathrm{D}$ heat conduction model, it was found that the size of the superheated region in the fluid just before bubble nucleation was comparable to the feature size of the micro heater, and it did not change much with an increase of the heat flux. The results of this investigation provide more information about the micro bubble generation process in DNA solutions, which have been extensively employed in DNA transport based on micro thermal ink-jet printer technology.

\section{Acknowledgment}

This work was supported by the Hong Kong Research Grant Council through RGC grant HKUST6014/02E and HKUST6134/04E.

\section{References}

[1] Cooley P, Wallace D and Antohe B 2001 Applications of ink-jet printing technology to bioMEMS and biofluidic systems Proc. SPIE Conf. on Microfluidics and BioMEMS (October) pp 177-88

[2] Eichenlaub U, Berger B, Finckh P, Karl J, Hornauer H, Weinreich G, Weindel K, Lenz H, Sluka P and Ekins R 1998 Microspot - a highly integrated ligand binding assay technology Proc. Int. Conf. on Microreaction Technology (New Orleans, LA) pp 134-8

[3] Gue A, Phou T, Jugieu D and Conedera V 2003 An ejection microarray for in-situ oligonucleotide synthesis on DNA chips Transducers'03: 12th Int. Conf. on Solid-State Sensors, Actuators and Microsystems (Boston, MA, 8-12 June) pp 218-21

[4] Blanchard A, Kaiser R and Hood L 1996 High density oligonucleotide arrays Biosens. Bioelectron. 11 687-90

[5] Okamoto T, Suzuki T and Yamamoto N 2000 Microarray fabrication with covalent attachment of DNA using bubble jet technology Nat. Biotechnol. 18 438-41

[6] Cooley P, Hinson D, Trost H, Antohe B and Wallace D 2001 Ink-jet deposited microspot arrays of DNA and other bioactive molecules Methods in Molecular Biology (DNA Arrays, Methods and Protocols, vol 170) (Totowa, NJ: Humana)

[7] Choi C 2003 Ink-jet printing creates tubes of living tissue New Sci. 22 January (http://www.newscientist.com/news/ news.jsp?id=ns99993292)

[8] Deng P G, Lee Y K and Cheng P 2003 The growth and collapse of a micro-bubble under pulse heating Int. J. Heat Mass Transfer 46 4041-50

[9] Deng P G, Lee Y K and Cheng P 2003 Design and characterization of a micro single bubble actuator Transducers' 03: 12th Int. Conf. on Solid-State Sensors, Actuators and Microsystems (Boston, MA, 8-12 June) pp 647-50

[10] Deng P G, Lee Y K and Cheng P 2004 Micro bubble dynamics in DNA solutions J. Micromech. Microeng. 14 693-701

[11] Deng P G, Lee Y K and Cheng P 2004 Viscosity effects on micro bubble actuator in ssDNA solutions 17th IEEE Int. Conf. on Micro Electro Mechanical Systems, MEMS 2004 (Maastricht) pp 292-5

[12] Avedisian C T, Osborne W S, Mcleod F D and Curley C M 1999 Measuring bubble nucleation temperature on the surface of a rapidly heated thermal ink-jet heater immersed in a pool of water Proc. R. Soc. A 455 3875-99

[13] Gold S, Poulikakos D, Zhao Z and Yadigaroglu G 2002 An investigation of microscale explosive vaporization of water on an ultrathin Pt wire Int. J. Heat Mass Transfer 45 367-79

[14] Yin Z, Prosperetti A and Kim J 2004 Bubble growth on an impulsively powered microheater Int. J. Heat Mass Transfer 47 1053-67

[15] Tsai J and Lin L 2002 Transient thermal bubble formation on polysilicon microresistors ASME J. Heat Transfer 124 375-82

[16] Schmidt E M 1983 Parylene as an electrode insulator-a review J. Electrophysiol. Technol. 10 19-29

[17] Cantor C R and Schimmel P R 1980 Biophysical Chemistry, Part III: The Behavior of Biological Macromolecules (San Francisco: W H Freeman) 
[18] Skripov V P 1974 Metastable Liquids (New York: Wiley)

[19] Iida U, Okuyama K and Sakurai K 1994 Boiling nucleation on a very small film heater subjected to extremely rapid heating Int. J. Heat Mass Transfer $\mathbf{3 7}$ 2771-80

[20] Lin L 1998 Microscale thermal bubble formation: thermophysical phenomena and applications Microscale Thermophys. Eng. 2 71-85
[21] Yang W J and Tsutsui K 2000 Overview of boiling on microstructures-macro bubbles from micro heater Microscale Thermophys. Eng. 4 7-24

[22] Asai A 1991 Bubble dynamics in boiling under high heat flux pulse heating J. Heat Transfer 113 973-8

[23] Oh S-D, Seung S S and Kwaw H Y 1999 A model of bubble nucleation on a micro line heater J. Heat Transfer 121 $220-5$ 